\title{
Analysis of Cases Referred for Psychiatric Evaluation after Mobbing
}

\author{
Mete Ercis, Olcay Şenay, Sevim Öncül, Doğan Şahin
}

Department of Psychiatry, Istanbul Medical Faculty, Istanbul University, Turkey

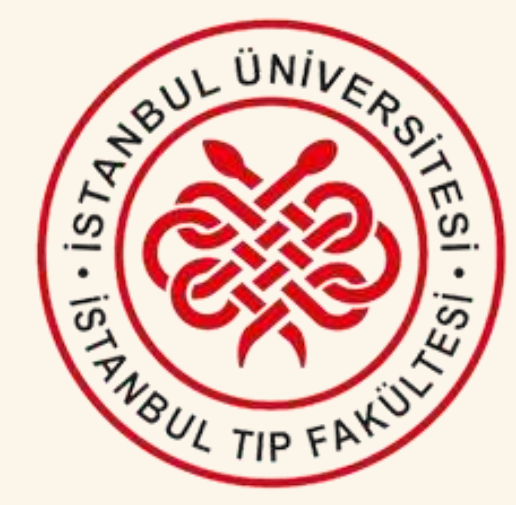

\section{Objectives}

To analyze sociodemographic features and psychometric properties of mobbing cases referred for psychiatric evaluation.

\section{Background and aims}

Mobbing (workplace harassment) research has gained attention in the last decades. Previous studies have shown that a significant number of mobbing victims have various depressive and psychosomatic symptoms $(1,2)$. Our aim is to determine the sociodemographic characteristics, frequency of mobbing, and to investigate the prevalence of psychiatric and other medical disorders after mobbing of the patients referred to a university hospital as a part of forensic evaluation. So it will be possible to understand which victim characteristics and workplace environment features leads to mobbing.

\section{Materials and methods}

Data were collected retrospectively by scanning files of the cases referred to our clinic from Istanbul Medical Faculty Forensic Medicine Department. Of the 61 cases referred in between 2010-2018 for allegedly been exposed to workplace harassment, we excluded 8 cases which mobbing was not detected, and remaining 53 cases were included in the study.

Type of mobbing was delineated according to Leymann Inventory of Psychological Terror (LIPT) for every victim: Effects on self-expression and communication; on social contacts; on personal reputation; on occupational situation and quality of life; on physical health. Both psychiatric and physical consequences of mobbing were noted. Further analyses were carried out in 33 cases that had MMPI test.

\section{Results}

$66 \%$ of the cases were women. $94 \%$ of victims had at least undergraduate degree. $39,6 \%$ were working in education services, $17,0 \%$ were in private company, $17,0 \%$ were in administrative business and $11,3 \%$ were in health services. $62.7 \%$ of the cases had been still working in the same workplace at time of evaluation.

Victims diagnoses according to DSM-5 are shown in Graph 1.

\section{Graph 1: Diagnoses According to DSM-5}

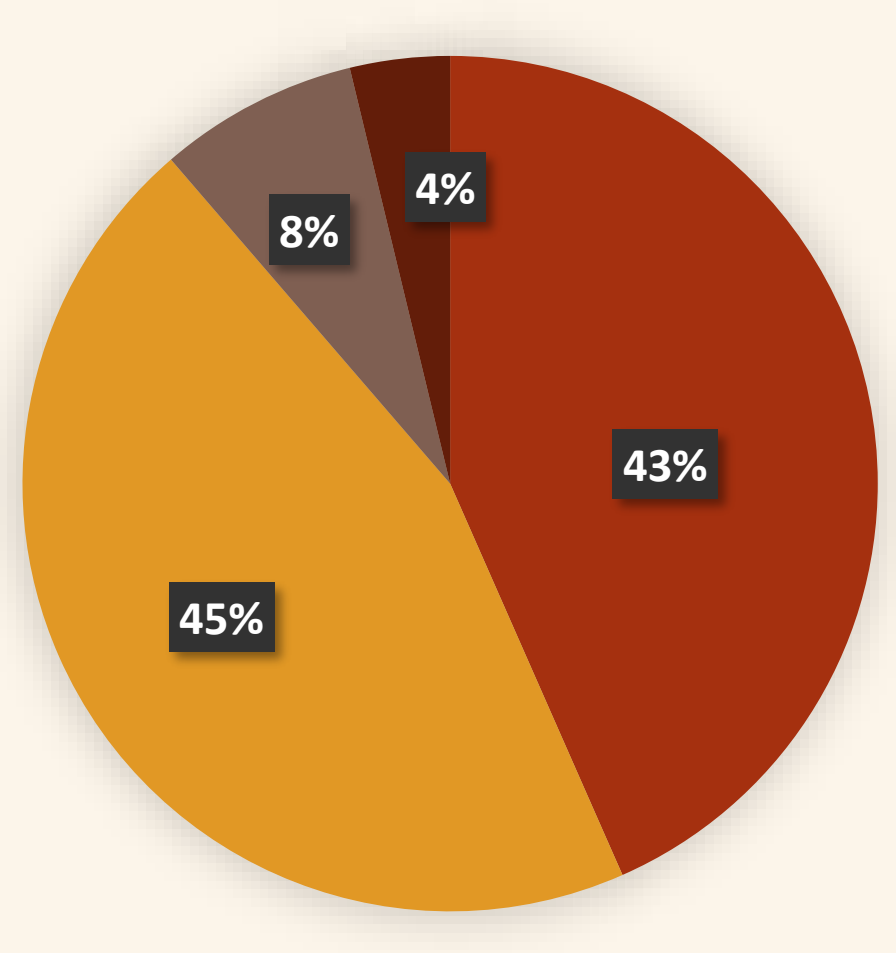

Major Depressive Disorder

- Trauma Related Disorders

Anxiety Disorders

- Somatic Symptom and Related Disorders

\section{Graph 2: Mean MMPI Scores}

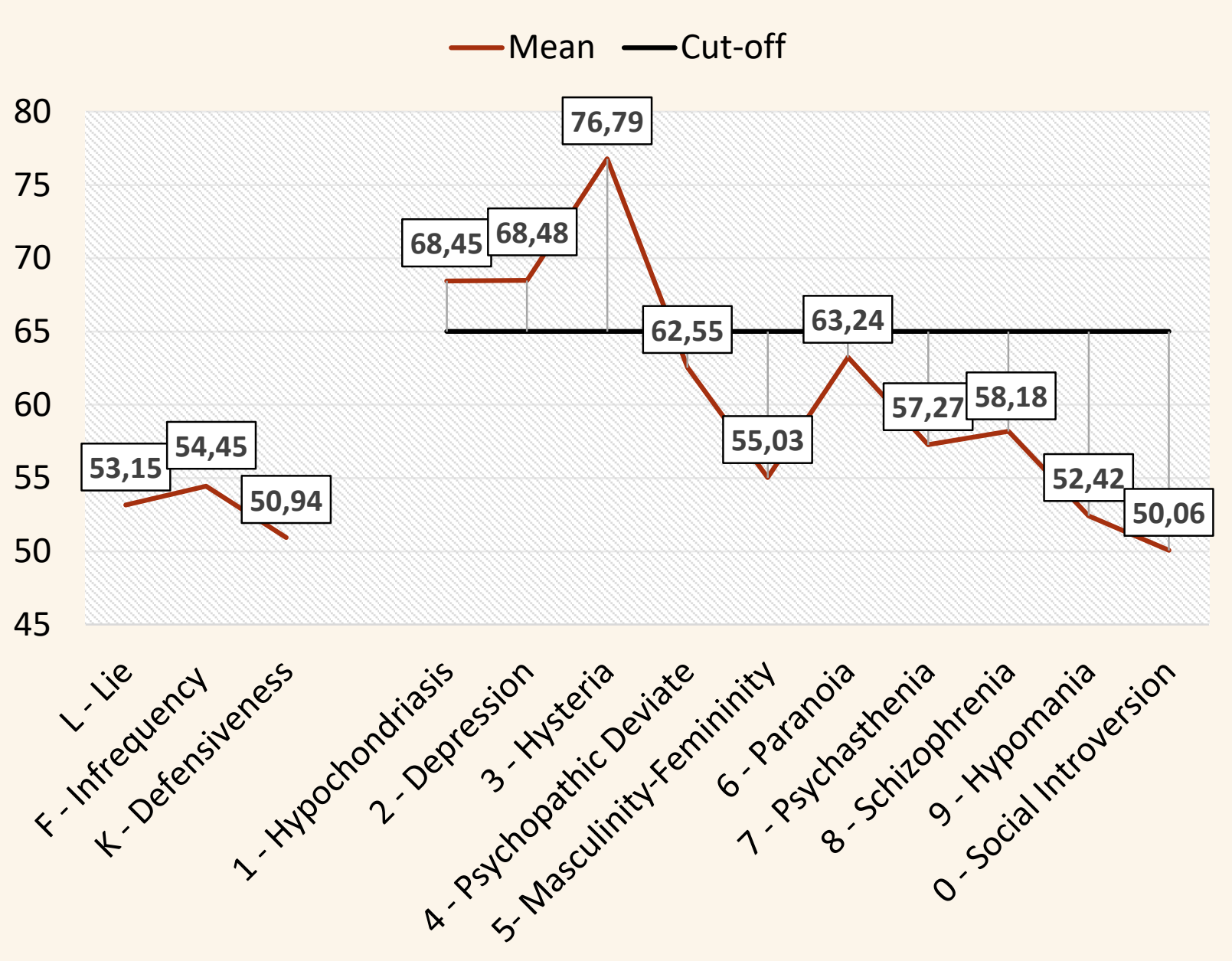

hypochondria and hysteria subscales were greater than cut-off score of 65 (Graph 2). Those who were affected in occupational situation and quality of life had higher depression $(p=0,022)$, psychopathic deviate $(p=0,002)$, and social introversion $(p=0,04)$ scores in MMPI.

\section{Conclusions}

Mobbing is a type of psychological trauma that might have significant psychiatric consequences. In our study, it was remarkable that victims had high education level. Yet, it was not possible to assess whether this is due to people with higher education are exposed to more workplace harassment or that they are more likely to take legal actions.

In previous studies on mobbing that used MMPI; depressive mood, difficulty in decision-making, passive aggressive features, somatic symptoms and paranoid tendency $(3,4)$ were noted. In our case series, depression, hypochondria and hysteria subscales exceeded the cut-off scores and this is in line with previous research. The question of whether psychopathologies detected after mobbing are result of workplace harassment or there had already been some psychopathological characteristics before is unanswered.

More research should be carried out to understand mobbing, its relationship between personality traits and prevent related disability.

\footnotetext{
Sources

1. Kreiner B, Sulyok $C$, Rothenhäusler HB. Does mobbing cause posttraumatic stress disorder? Impact of coping and personality. Neuropsychiatr. 2008;22(2):112-23.

2. Figueiredo-Ferraz H, Gil-Monte PR, Olivares-Faúndez VE. Influence of mobbing (workplace bullying) on depressive symptoms: a longitudinal study among employees working with people with intellectual disabilities. J Intellect Disabil Res. 2015 Jan;59(1):39-47.

3. Girardi P, Monaco E, Prestigiacomo C, Talamo A, Ruberto A, Tatarelli R. Personality and psychopathological profiles in individuals exposed to mobbing. Violence and Victims 2007;22 (2), 172-188

4. Gandolfo R. MMPI-2 profiles of worker's compensation claimants who present with complaints of harassment. Journal of Clinical Psychology 1995;51 (5), 711-715.
} 